\title{
Employment Loss as a Result of COVID-19: a Nationwide Survey at the Onset of COVID-19 in US LGBTQ+ Populations
}

\author{
Richard J. Martino ${ }^{1} \cdot$ Kristen D. Krause $^{1,3} \cdot$ Marybec Griffin $^{1} \cdot$ Caleb LoSchiavo $^{1} \cdot$ Camilla Comer-Carruthers $^{1}$. \\ Perry N. Halkitis ${ }^{1,2,3}$ (D)
}

Accepted: 28 October 2021 / Published online: 13 November 2021

(c) The Author(s), under exclusive licence to Springer Science+Business Media, LLC, part of Springer Nature 2021

\begin{abstract}
Introduction The unemployment rate in the US reached record highs during the COVID-19 pandemic, but little is known about the job loss experiences of lesbian, gay, bisexual, transgender, and queer (LGBTQ+) individuals, who are already economically disadvantaged due to structural and social inequities.

Methods Cross-sectional data on unemployment due to COVID-19 were collected between May and July 2020 among 1090 individuals across the US through an online survey.

Results Respondents who had been employed prior to COVID-19 formed the analytic sample $(n=990)$. Of these, 298 (27.3\%) reported job loss or being furloughed due to COVID-19. When controlling for all other factors, we found statistically significant higher rates of unemployment among younger participants, HIV-positive individuals, men, Black and White non-Hispanic participants, those with less educational attainment, and those in multi-person homes.

Conclusions The employment of LGBTQ+ people has been undermined by COVID-19, but as with all populations, those with multiple minority identities, such as Black or HIV+ and LGBTQ+, have been most severely affected.

Policy Implications LGBTQ+ populations in the US have experienced high levels of unemployment due to COVID-19. This study highlights the need for national data collection on sexual orientation and gender identity for unemployment as well as the need for substantive policies, such as expanding unemployment to assist in the economic recovery for populations most affected by COVID-19 and the Equality Act to offer further workplace protections.
\end{abstract}

Keywords COVID-19 $\cdot$ Unemployment $\cdot$ LGBTQ $\cdot$ Sexual and gender minority $\cdot$ Health equity

\section{Introduction}

Throughout the United States (US), the novel coronavirus (SARS-CoV-2) led to a further loss of human life and impacted the health and livelihoods of the population. In the US, there have been over 30 million cases, 546,000 deaths, and 30 million people filing for unemployment attributed

Perry N. Halkitis

perry.halkitis@rutgers.edu

1 Center for Health, Identity, Behavior, and Prevention Studies (CHIBPS), Rutgers School of Public Health, Rutgers University, Newark, NJ, USA

2 Department of Biostatistics and Epidemiology, Rutgers School of Public Health, Rutgers University, Piscataway, NJ, USA

3 Department of Urban-Global Health, Rutgers School of Public Health, Rutgers University, Newark, NJ, USA to the coronavirus disease (COVID-19) by February 2021 (Centers for Disease Control and Prevention, 2020a; US Department of Labor, 2020b). COVID-19 has disproportionally affected racial and ethnic minority populations (Abuelgasim et al., 2020; Chen et al., 2021; Laurencin \& McClinton, 2020; Rossen et al., 2020), immigrant populations (Clark et al., 2020), and individuals without insurance and underinsured (Rader et al., 2020) and stable housing (Ahmad et al., 2020). The COVID-19 pandemic has exacerbated inequalities throughout the US, including economic inequalities as seen through job loss.

The US unemployment rate dramatically increased due to COVID-19, while those who were employed in food, transportation, and retail sectors experienced higher excess mortality, especially for workers in racial and ethnic minority groups (Chen et al., 2021). As of December 2020, the US unemployment rate was $6.2 \%$ or about $8 \%$ lower than the start of COVID-19 in April 2020, which was the 
highest unemployment rate since the Great Depression (Fairlie et al., 2020; US Department of Labor, 2020b). The US Household Pulse Survey in March 2021 found $31 \%$ of adults surveyed had a high likelihood of eviction or foreclosure and $19 \%$ of adults expected someone in the household to have a loss of income in the next four weeks (US Census Bureau, 2021a). The US federal government passed the Coronavirus Aid, Relief, and Economic Security (CARES) Act in March 2020 to provide financial relief for small businesses, unemployed persons, and those with student loans (US Department of Treasury, 2020). Before the Consolidated Appropriates Act, 2021, which included COVID-19 stimulus relief, was signed into law on December 27, 2020 (The Associated Press, 2020; US Congress, 2021), an estimated 12 million people would have lost unemployment benefits (Stettner \& Pancotta, 2020) and 6.7 million households faced possible eviction (Threet et al., 2020). Further support from the US government with the American Rescue Plan includes direct economic relief, funding to reopen schools, and funding for community vaccination efforts (The White House, 2021; US Department of Treasury, 2021). Targeted policies to support those most affected by COVID-19 are needed for long-term economic recovery.

Information on jobs loss and financial strain due to the COVID-19 pandemic among lesbian, gay, bisexual, transgender, and queer (LGBTQ+) populations within the US is limited. Sexual orientation and gender identity (SOGI) data are not regularly collected for national COVID-19 reports and previous national surveys reported LGBTQ+ household data, which can miss a large part of the LGBTQ+ population (Jones, 2017; Krause, 2021; Mirza et al., 2018; Movement Advancement Project, 2020). The lack of SOGI data is concerning given that sexual and gender minorities (SGM) often experience higher rates of adverse health outcomes, such as barriers to healthcare (Griffin et al., 2018, 2020a; Heck et al., 2006), homelessness (Castellanos, 2016; Ecker et al., 2019; Krause et al., 2016), mental health burdens (Russell \& Fish, 2016; Su et al., 2016), and intimate partner violence (Walters et al., 2011). The economic disparities between SGM and nonSGM populations have existed before the COVID-19 pandemic (Carpenter et al., 2020; Charlton et al., 2018; The Williams Institute, 2019), and these disparities may continue to worsen during the pandemic as SGM in the US have experienced a greater risk of job loss and economic uncertainty compared to the non-SGM population, especially for Black LGBTQ+ households (Human Rights Campaign Foundation \& PSB, 2020; Movement Advancement Project, 2020; Whittington et al., 2020). This study aims to describe job loss among the LGBTQ+ population within the US and identify demographic differences in job loss among this diverse LGBTQ+ population.

\section{Methods}

This cross-sectional study examined experiences due to COVID-19 among LGBTQ+ individuals in the US through an internet-based survey from May 2020 through July 2020. Study design and recruitment strategies have been previously described in more detail (Martino et al., 2021). To summarize, eligibility criteria included participants who were 18 years or older, identified LGBTQ+, and lived in the US, including the US territories. The survey was only available in English. The survey was conducted through Qualtrics (Qualtrics, 2005) with participants recruited online through listservs of academic and professional organizations, such as American Psychological Association, and through social media LGBTQ+ groups and social media posts by accounts of the research center and research staff. Data collection occurred in two waves, Wave I (May 7-8, 2020) and Wave II (June 11 to July 31,2020 ) due to the detection of bots attempting to claim gift cards in Wave I. Responses flagged as bots by Google reCaptcha (Google, 2020) or had inconsistencies, such as duplicate responses for qualitative questions, were removed from the study sample. Further detail on bot removal has been described previously (Griffin et al., 2021). Eligible participants were offered a $\$ 5$ electronic gift card in Wave I and the chance to win one of ten $\$ 100$ gift cards in a raffle for Wave II. To protect against bots in Wave II, we implemented IP address checks and repeated questions to check for consistency. All study activities were approved by the Institutional Review Board at Rutgers University (\#Pro2020000920).

\section{Study Population and Measures}

The total sample of study participants was 1090 LGBTQ+ participants. Wave I had 477 participants, while Wave II had 613 participants with no demographic (i.e., race/ ethnicity, gender identity, sexual orientation) differences between both groups. Participants self-reported all data including demographic characteristics and employment data. We used March 13, 2020, as the onset of the pandemic.

For demographic characteristics, participants reported their sex assigned at birth, gender identity, sexual orientation, age, and race/ethnicity. Sexual orientation and gender identity were collapsed into one variable to analyze the nuanced interaction between the two demographic characteristics. For the analyses, participants who reported their sexual orientation as bisexual or other were collapsed into one group for each gender identity due to the small sample sizes. Participants were asked their nation of birth, which we dichotomized as born outside the US and US born, 
HIV status, and education attainment, which we collapsed into high school/GED or less, some college or associate's degree, and bachelor's degree or graduate degree. We collected the number of people living in the household and the US Postal Service ZIP codes of current residence, which we matched to US states and territories to create six US regions (Northeast, Midwest, Mountain, Pacific, South, and Non-Contiguous U.S regions) (Florida, 2019; Jean, 1957).

Participants were asked their employment status and a series of questions depending on whether they were employed or unemployed. Those who were employed were asked to report if they were self-employed, worked from home before and after March 13, 2020, and if they were essential workers. Participants who were unemployed were asked if they lost their job as a result of the coronavirus. All participants were asked if they were furloughed from their job as a result of coronavirus.

\section{Statistical Analyses}

Descriptive statistics were reported for all variables. Participants who reported either job loss or furloughed from their job due to COVID-19 were grouped into the unemployment due to COVID-19, while those who reported full-time employment or part-time employment were grouped into the employed group. To get a clear understanding of the differences of employment due to COVID-19, the 100 participants who reported unemployment both before and after the COVID-19 pandemic were excluded from the analyses. We analyzed differences in demographic characteristics between participants who were employed and unemployed due to COVID-19 with chi-squared tests. We then conducted logistic regression analyses to better understand the outcome of unemployment due to COVID-19. An alpha level of 0.05 was used to assess significance, and all analyses were conducted with SAS 9.4 (TS1M5) (SAS Institute Inc, 2016).

\section{Results}

Overall, 1090 study participants across the US completed the survey (Table 1). Ages ranged from 18 to 81 years (median 30 , mean 33.88, standard deviation 11.85 ) and a majority of participants identified as White non-Hispanic (69\%), followed by Black non-Hispanic (11\%), and Hispanic/Latinx $(10 \%)$. In terms of gender and sexual orientation, the study drew upon a diverse sample. A majority of participants had completed a bachelor's degree or more education (71\%) and reported being HIV-negative (79\%). For relationship status, participants reported an even distribution between single, in a committed relationship, and married or in a domestic partnership. Most participants (83\%) reported that their current living situation was the same as before the start of the pandemic and $12 \%$ of participants reported living alone. A large majority of participants were born in the US (93\%), and there was a diverse distribution of current place of residence by US region.

Of the 1090 participants, 215 (20\%) participants were unemployed, and among those who were unemployed, 109 (51\%) reported that they lost their job as a result of the coronavirus. Of the 1090 participants, 246 (22.6\%) participants were furloughed from their job due to COVID-19, while 875 (80\%) participants reported some type of employment. Of the 875 employed participants, 136 (16\%) were self-employed and $642(73 \%)$ were currently working from home.

To better understand differences in economic loss among the population, participants who reported either job loss or furlough due to COVID-19 were considered unemployed due to COVID-19 $(n=298)$ were compared to those who reported current employment $(n=692)$ (Table 2). Job loss differed across all sociodemographic variables, except for nation of birth and change in current living situation. Those in younger age groups reported high frequencies of unemployment due to COVID-19 $\left(\chi^{2}=62.05, \mathrm{df}=3, p=<.001\right)$ with job loss reported by $42 \%$ of participants in the 18-29 age group and $24 \%$ participants in the 30-39 age groups. Among racial/ethnic groups, job loss within Native American/Other and Black non-Hispanic groups were highest with $45 \%$ and $43 \%$, respectively $\left(\chi^{2}=20.66, \mathrm{df}=5, p=<.001\right)$. Furthermore, there were significant differences in job loss among sexual orientation and gender $\left(\chi^{2}=35.98, \mathrm{df}=9\right.$, $p=<.001)$. Participants were more likely to report being employed if they had at least a bachelor's degree $\left(81 \% ; \chi^{2}\right.$ $=134.97, \mathrm{df}=2, p=<.001$ ), were not currently enrolled in school $\left(72 \%, \chi^{2}=7.04, \mathrm{df}=1, p=<.001\right)$, were employed full time $\left(83 \%, \chi^{2}=30.82, \mathrm{df}=1, p=<.001\right)$, were living in the Northeast $\left(79 \% ; \chi^{2}=35.57, \mathrm{df}=5, p=<.001\right)$, and were HIV-negative $\left(75 \% ; \chi^{2}=38.12, \mathrm{df}=2, p=<.001\right)$. In addition, $54 \%$ of those living with $4-5$ other people and $39 \%$ of these living with 2-3 other people reported job loss due to COVID-19 $\left(\chi^{2}=85.44, \mathrm{df}=4, p=<.001\right)$.

Logistic regression analyses were conducted to model unemployment due to COVID-19 (Table 3). Unadjusted odds ratios $(\mathrm{OR})$ and adjusted odds ratio $(\mathrm{aOR})$ were reported for the sociodemographic variables that were significant in the chisquare analyses (Table 2 ). The adjusted model was statistically significant $\left(\chi^{2}=243, \mathrm{df}=33, p=<.001\right.$, classification fit $=$ $86 \%$ ). The younger participants in the 18-29 and 30-39 age groups indicated 6.78 and 2.95 times the odds of unemployment due to COVID-19, respectively, compared to the 50+ age group. Compared to Hispanic/Latinx participants, Black non-Hispanic and White non-Hispanic participants reported higher rates of job loss. Gay cisgender and transgender men indicated 2.25 and 5.74 times the odds of job loss compared to bisexual and other sexual orientation women, respectively. Participants with a high school education or less indicated 2.63 
Table 1 Demographic and employment characteristics during the COVID-19 pandemic, $n=1090,2020$, USA
$\mathrm{Age}$

$18-29$

30-39

40-49

$50+$

$n$

Race and ethnicity
Asian/Pacific Islander non-Hispanic
Black non-Hispanic
Hispanic/Latinx
Multiracial
Native American/Other
White non-Hispanic

Sexual orientation and gender identity

Gay cis men

Bi cis men

Other sexual orientation cis men

Lesbian cis women

Bi cis women

Other sexual orientation cis women

Gay trans men

Bi trans men

Other sexual orientation trans men

Lesbian trans women

Bi trans women

Other sexual orientation trans women

Gay/Lesbian non-binary

Bi non-binary

Other sexual orientation non-binary

Educational attainment

High school/GED or less

Some college/Associates degree

Bachelor's degree or more

Education status

Currently enrolled in school

Not currently enrolled in school

HIV status

Positive

9.1

Negative

Unknown

Relationship status

Single

In a committed relationship

Married or domestic partnership

Separated, widowed, or divorced

Nation of birth

Outside USA

USA

US region

Northeast

420

Midwest

South 
Table 1 (continued)

\begin{tabular}{|c|c|c|}
\hline & $n$ & $\%$ \\
\hline Mountain & 104 & 9.5 \\
\hline Pacific & 177 & 16.2 \\
\hline Non-contiguous & 30 & 2.8 \\
\hline \multicolumn{3}{|c|}{ Number of people living with participant } \\
\hline Lives alone & 133 & 12.3 \\
\hline 1 & 364 & 33.6 \\
\hline $2-3$ & 450 & 41.5 \\
\hline $4-5$ & 112 & 10.3 \\
\hline $6+$ & 26 & 2.4 \\
\hline \multicolumn{3}{|l|}{ Employment } \\
\hline Unemployed & 215 & 19.7 \\
\hline Employed, full time & 643 & 59 \\
\hline Employed, part time & 232 & 21.3 \\
\hline \multicolumn{3}{|l|}{ Self-employed $(n=875)$} \\
\hline No & 739 & 84.5 \\
\hline Yes & 136 & 15.5 \\
\hline \multicolumn{3}{|c|}{ Worked from home before March 13, $2020(n=875)$} \\
\hline No & 711 & 81.3 \\
\hline Yes & 164 & 18.7 \\
\hline \multicolumn{3}{|c|}{ Currently work from home $(n=875)$} \\
\hline No & 233 & 26.6 \\
\hline Yes & 642 & 73.4 \\
\hline \multicolumn{3}{|c|}{ Essential workers $(n=874)$} \\
\hline No & 604 & 69.1 \\
\hline Yes & 270 & 30.9 \\
\hline \multicolumn{3}{|c|}{ Job loss as a result of the coronavirus (COVID-19) $(n=215)$} \\
\hline No & 106 & 49.3 \\
\hline Yes & 109 & 50.7 \\
\hline \multicolumn{3}{|c|}{ Furloughed from job as a result of the coronavirus (COVID-19) } \\
\hline No & 844 & 77.4 \\
\hline Yes & 246 & 22.6 \\
\hline
\end{tabular}

times the odds and participants with some college or an associate's degree indicated 3.37 times the odds of job loss compared to participants with a bachelor's degree or more education. Participants who reported being HIV-positive indicated 2.39 times the odds of job loss compared to participants who reported being HIV-negative. Participants who reported living with 2-3 other people and with 4-5 other people indicated 6.04 times the odds and 10.28 times the odds of job loss, respectively, compared to participants that reported living alone. Differences in job loss by US regions, current education status, and employment type were not statistically significant.

\section{Discussion}

The cross-sectional study of COVID-19 experiences among LGBTQ+ individuals in the US found that the population experienced high rates of job loss. We found that participants who experienced greater job loss within the LGBTQ+ population were younger in age, Black nonHispanic and White non-Hispanic, gay cisgender men, individuals with an associate's degree or high school education, HIV-positive, and living with 2-5 other people. Among the 1090 surveyed, 298 (27.3\%) reported job loss due to COVID-19 compared to the national average of $13.3 \%$ in May 2020 (US Department of Labor, 2020a). Previously LGBTQ+ households reported higher rates of financial problems and job loss compared to non-LGBTQ+ households (Movement Advancement Project, 2020). We have conducted one of the first studies to report job loss within the US LGBTQ+ population during the COVID-19 pandemic to better understand the nuanced experiences of individuals within the LGBTQ+ community.

We found that younger LGBTQ+ individuals were more likely to report unemployment due to COVID-19 when controlling for all other characteristics. Younger individuals 
Table 2 Job loss due to COVID-19 by demographic characteristics, insurance, and living arrangement, $n=990$, 2020, USA

\begin{tabular}{|c|c|c|c|c|c|}
\hline & \multicolumn{2}{|c|}{$\begin{array}{l}\text { Employed } \\
n=692\end{array}$} & \multicolumn{2}{|c|}{$\begin{array}{l}\text { Unemployed due to } \\
\text { COVID-19 } \\
n=298\end{array}$} & \multirow[t]{2}{*}{$p$} \\
\hline & $n$ & $\%^{\mathrm{a}}$ & $n$ & $\%^{\mathrm{a}}$ & \\
\hline Age & & & & & $<.001$ \\
\hline $18-29$ & 255 & 58.0 & 185 & 42.1 & \\
\hline $30-39$ & 255 & 75.4 & 83 & 24.6 & \\
\hline $40-49$ & 85 & 81.7 & 19 & 18.3 & \\
\hline $50+$ & 97 & 89.8 & 11 & 10.2 & \\
\hline Race and ethnicity & & & & & $<.001$ \\
\hline Asian/Pacific Islander non-Hispanic & 29 & 69.1 & 13 & 31.0 & \\
\hline Black non-Hispanic & 66 & 57.4 & 49 & 42.6 & \\
\hline Hispanic/Latinx & 74 & 79.6 & 19 & 20.4 & \\
\hline Multiracial & 30 & 88.2 & 4 & 11.8 & \\
\hline Native American/Other & 12 & 54.6 & 10 & 45.5 & \\
\hline White non-Hispanic & 481 & 70.3 & 203 & 29.7 & \\
\hline Sexual orientation and gender identity & & & & & $<.001$ \\
\hline Gay cis men & 239 & 64.6 & 131 & 35.4 & \\
\hline Bi/Other sexual orientation cis men & 53 & 69.7 & 23 & 30.3 & \\
\hline Lesbian cis women & 117 & 66.5 & 59 & 33.5 & \\
\hline $\mathrm{Bi} /$ Other sexual orientation cis women & 146 & 78.1 & 41 & 21.9 & \\
\hline Gay trans men & 6 & 37.5 & 10 & 62.5 & \\
\hline $\mathrm{Bi} /$ Other sexual orientation trans men & 23 & 85.2 & 4 & 14.8 & \\
\hline Lesbian trans women & 5 & 50.0 & 5 & 50.0 & \\
\hline $\begin{array}{l}\text { Bi/Other sexual orientation trans } \\
\text { women }\end{array}$ & 15 & 68.2 & 7 & 31.8 & \\
\hline Gay/Lesbian non-binary & 20 & 74.1 & 7 & 25.9 & \\
\hline Bi/Other sexual orientation non-binary & 68 & 86.1 & 11 & 13.9 & \\
\hline Education attainment & & & & & $<.001$ \\
\hline High school/GED or less & 28 & 41.2 & 40 & 58.8 & \\
\hline Some college/Associates degree & 91 & 43.3 & 119 & 56.7 & \\
\hline Bachelor's degree or more & 573 & 80.5 & 139 & 19.5 & \\
\hline Education status & & & & & 0.008 \\
\hline Currently enrolled in school & 167 & 63.5 & 96 & 36.5 & \\
\hline Not currently enrolled in school & 521 & 72.3 & 200 & 27.7 & \\
\hline Worked from home before March 13, 2020 & & & & & $<.001$ \\
\hline Yes & 106 & 64.6 & 58 & 35.4 & \\
\hline No & 586 & 82.4 & 125 & 17.6 & \\
\hline Employment type & & & & & $<.001$ \\
\hline Part time employment & 154 & 66.4 & 78 & 33.6 & \\
\hline Full time employment & 538 & 83.7 & 105 & 16.3 & \\
\hline US region & & & & & $<.001$ \\
\hline Northeast & 305 & 78.6 & 83 & 21.4 & \\
\hline Midwest & 80 & 69.6 & 35 & 30.4 & \\
\hline South & 135 & 67.5 & 65 & 32.5 & \\
\hline Mountain & 58 & 62.4 & 35 & 37.6 & \\
\hline Pacific & 94 & 59.9 & 63 & 40.1 & \\
\hline Non-contiguous & 12 & 41.4 & 17 & 58.6 & \\
\hline Nation of birth & & & & & 0.59 \\
\hline Outside USA & 48 & 72.7 & 18 & 27.3 & \\
\hline USA & 640 & 69.6 & 280 & 30.4 & \\
\hline HIV status & & & & & $<.001$ \\
\hline
\end{tabular}


Table 2 (continued)

\begin{tabular}{|c|c|c|c|c|c|}
\hline & \multicolumn{2}{|c|}{$\begin{array}{l}\text { Employed } \\
n=692\end{array}$} & \multicolumn{2}{|c|}{$\begin{array}{l}\text { Unemployed due to } \\
\text { COVID-19 } \\
n=298\end{array}$} & \multirow[t]{2}{*}{$p$} \\
\hline & $n$ & $\%^{\mathrm{a}}$ & $n$ & $\%^{\mathrm{a}}$ & \\
\hline Negative & 584 & 74.5 & 200 & 25.5 & \\
\hline Positive & 48 & 53.3 & 42 & 46.7 & \\
\hline Unknown & 58 & 51.3 & 55 & 48.7 & \\
\hline Number of people living with participant & & & & & $<.001$ \\
\hline Lives alone & 107 & 89.2 & 13 & 10.8 & \\
\hline 1 other person & 265 & 81.3 & 61 & 18.7 & \\
\hline 2-3 other people & 253 & 61.1 & 161 & 38.9 & \\
\hline $4-5$ other people & 47 & 45.6 & 56 & 54.4 & \\
\hline $6+$ other people & 17 & 73.9 & 6 & 26.1 & \\
\hline
\end{tabular}

${ }^{a}$ Row percent

In cases when sample size of cell was insufficnet, Fisher Exact Test was utilized

are possibly at an increased risk of job loss due to job type (Human Rights Campaign Foundation \& PSB, 2020; Kochhar \& Barroso, 2020). These findings are concerning given the lack of financial savings younger individuals have overall (Mottola, 2014), and the reduction in savings has been amplified due to the COVID-19 pandemic (Dickler, 2020; Royal, 2020). Job loss among younger adults due to COVID-19 has been associated with mental health burdens (Ganson et al., 2021). Our findings build off previous research and indicate that younger LGBTQ+ individuals are currently experiencing major financial insecurities due to unemployment.

Additionally, gay men reported greater job loss compared to cisgender women who identified as bisexual or another sexual orientation. These results are particularly salient because national unemployment surveys typically do not include unemployment data by SOGI on the individual level and are therefore lacking this important information during the COVID-19 pandemic (Krause, 2021). A previous study from the Williams Institute found that LGBTQ+ individuals experienced higher rates of poverty than cisgender; heterosexual individuals and that experience of unemployment for LGBTQ+ are complex and differ by specific SOGI groups (Badgett et al., 2019). Through the Household Pulse Survey, the US Census Bureau has published for the first time in July 2021 the employment experiences of LGBTQ+ households with $23 \%$ of LGBTQ+ households and $32 \%$ of transgender households experiencing loss of employment income within the last 4 weeks (US Census Bureau, 2021b).

Furthermore, we found that Black and White non-Hispanic participants reported greater job loss than Hispanic/Latinx participants. Certain racial/ethnic minority individuals are working more essential, frontline jobs, which has led to the high rates of infection and death within these populations (Cahill et al., 2020; Chen et al., 2021; Hsu et al., 2020), especially for
Hispanic/Latinx populations throughout the US (RodriguezDiaz et al., 2020; Vahidy et al., 2020). Participants with higher educational attainment were protected from job loss, which is consistent with the general US population (Centers for Disease Control and Prevention, 2020b).

It is concerning to report that people living with HIV are experiencing greater rates of job loss compared to participants who reported an HIV-negative status. People living with HIV are experiencing delays or interruptions in care (Sanchez et al., 2020; Santos et al., 2020), and multiple physical, psychosocial, and structural health burdens due to the COVID-19 (Shiau et al., 2020). With the increase in unemployment, LGBTQ+ individuals face the possibility of losing their health insurance leading to gaps in care (Griffin-Tomas et al., 2018; Griffin et al., 2020b; Mojtabai, 2019). While the CARES Act covers COVID-19-related care (US Department of Health \& Human Services, 2020), those who need medical attention may delay or not seek care due to perceived cost of care (Farmer, 2020), particularly when there have been reports that people have received surprise healthcare bills when seeking COVID-19 testing and care (CBS News, 2020; Rodriguez, 2020). The healthcare seeking behaviors of LGBTQ+ individuals are complex and may change as healthcare policies change throughout the COVID-19 pandemic. Previously, LGBTQ+ individuals were less likely to avoid care if they had insurance (GriffinTomas et al., 2018); however, they were more likely to have individually purchased insurance and avoid healthcare due to costs compared to heterosexual individuals (Nguyen et al., 2018). During the COVID-19 pandemic, families with privately purchased insurance and underinsured individuals were more likely to avoid care due to cost highlighting the need for expanding Medicaid coverage for individuals who fall into eligibly gaps or are under uninsured (Collins et al., 2020; Foster, 2020; Garfield et al., 2021; King, 2020). 
Table 3 Logistic regression models evaluating unemployment due to COVID19 for LGBTQ+ COVID-19 survey participants, 2020, USA $(n=990)$

\begin{tabular}{|c|c|c|c|c|c|c|}
\hline & OR & $95 \% \mathrm{CI}$ & $p$ & $\mathrm{aOR}^{\mathrm{a}}$ & $95 \% \mathrm{CI}$ & $p$ \\
\hline \multicolumn{7}{|l|}{ Age } \\
\hline $18-29$ & 6.40 & $(3.33,12.28)$ & $<.001$ & 7.43 & $(2.96,21.79)$ & $<.001$ \\
\hline $30-39$ & 2.87 & $(1.47,5.61)$ & 0.002 & 2.97 & $(1.17,8.74)$ & 0.032 \\
\hline $40-49$ & 1.97 & $(0.89,4.38)$ & 0.1 & 2.49 & $(0.73,8.81)$ & 0.1445 \\
\hline $50+$ & Ref & & & Ref & & \\
\hline \multicolumn{7}{|l|}{ Race and ethnicity } \\
\hline Asian/Pacific Islander non-Hispanic & 1.75 & $(0.76,3.99)$ & 0.19 & 2.54 & $(0.59,10.39)$ & 0.20 \\
\hline Black non-Hispanic & 2.89 & $(1.55,5.40)$ & $<.001$ & 5.57 & $(2.10,16.13)$ & $<.001$ \\
\hline Multiracial & 0.52 & $(0.16,1.66)$ & 0.27 & 0.95 & $(0.18,2.72)$ & 0.96 \\
\hline Native American/Other & 3.25 & $(1.22,8.64)$ & 0.018 & 4.58 & $(0.77,25.01)$ & 0.083 \\
\hline White non-Hispanic & 1.64 & $(0.97,2.79)$ & 0.066 & 5.04 & $(2.13,13.42)$ & $<.001$ \\
\hline Hispanic/Latinx & Ref & & & Ref & & \\
\hline \multicolumn{7}{|l|}{ Sexual orientation and gender identity } \\
\hline Gay cis men & 1.95 & $(1.30,2.93)$ & 0.001 & 2.25 & $(1.23,4.19)$ & 0.010 \\
\hline $\mathrm{Bi} /$ Other sexual orientation cis men & 1.55 & $(0.85,2.82)$ & 0.15 & 1.39 & $(0.62,3.06)$ & 0.42 \\
\hline Lesbian cis women & 1.80 & $(1.13,2.86)$ & 0.014 & 1.18 & $(0.59,2.37)$ & 0.63 \\
\hline Gay trans men & 5.94 & $(2.04,17.30)$ & 0.001 & 5.74 & $(1.20,28.99)$ & 0.029 \\
\hline $\mathrm{Bi} /$ Other sexual orientation trans men & 0.62 & $(0.20,1.89)$ & 0.40 & 0.54 & $(0.07,2.44)$ & 0.48 \\
\hline Lesbian trans women & 3.56 & $(0.98,12.90)$ & 0.053 & 0.34 & $(0.01,4.94)$ & 0.46 \\
\hline $\mathrm{Bi} /$ Other sexual orientation trans women & 1.66 & $(0.64,4.35)$ & 0.30 & 0.89 & $(0.19,3.58)$ & 0.87 \\
\hline Gay/Lesbian non-binary & 1.25 & $(0.49,3.15)$ & 0.64 & 0.38 & $(0.05,1.77)$ & 0.26 \\
\hline $\mathrm{Bi} /$ Other sexual orientation non-binary & 0.58 & $(0.28,1.19)$ & 0.14 & 0.43 & $(0.13,1.20)$ & 0.13 \\
\hline $\mathrm{Bi} /$ Other sexual orientation cis women & Ref & & & & & \\
\hline \multicolumn{7}{|l|}{ Education attainment } \\
\hline High school/GED/trade school or less & 5.89 & $(3.51,9.88)$ & $<.001$ & 2.63 & $(1.23,5.66)$ & 0.013 \\
\hline Some college/associates degree & 5.39 & $(3.88,7.50)$ & $<.001$ & 3.37 & $(2.06,5.53)$ & $<.001$ \\
\hline Bachelor's degree (4-year college) or more & Ref & & & Ref & & \\
\hline \multicolumn{7}{|l|}{ Education status } \\
\hline Currently enrolled in school & 1.50 & $(1.11,2.02)$ & 0.008 & 1.00 & $(0.62,1.60)$ & 0.99 \\
\hline Not currently enrolled in school & Ref & & & Ref & & \\
\hline Worked from home before March 13, 2020 & & & $<.001$ & & & 0.11 \\
\hline Yes & 2.57 & $(1.76,3.72)$ & & 1.50 & $(0.90,2.45)$ & \\
\hline No & Ref & & & Ref & & \\
\hline \multicolumn{7}{|l|}{ Employment type } \\
\hline Part time employment & 2.60 & $(1.84,3.66)$ & $<.001$ & 1.52 & $(0.95,2.43)$ & 0.080 \\
\hline Full time employment & Ref & & & Ref & & \\
\hline \multicolumn{7}{|l|}{ US region } \\
\hline Midwest & 1.61 & $(1.01,2.56)$ & 0.08 & 1.10 & $(0.54,2.18)$ & 0.79 \\
\hline Mountain & 2.22 & $(1.37,3.60)$ & 0.050 & 1.73 & $(0.81,3.60)$ & 0.15 \\
\hline Non-contiguous & 5.21 & $(2.39,11.33)$ & 0.001 & 2.11 & $(0.67,6.85)$ & 0.21 \\
\hline Pacific & 2.46 & $(1.65,3.68)$ & $<.001$ & 1.45 & $(0.77,2.68)$ & 0.24 \\
\hline South & 1.77 & $(1.21,2.59)$ & $<.001$ & 1.36 & $(0.76,2.41)$ & 0.30 \\
\hline Northeast & Ref & & & Ref & & \\
\hline \multicolumn{7}{|l|}{ HIV status } \\
\hline Positive & 2.56 & $(1.64,3.98)$ & $<.001$ & 2.39 & $(1.18,4.86)$ & 0.015 \\
\hline Unknown & 2.77 & $(1.85,4.14)$ & $<.001$ & 1.99 & $(1.11,3.55)$ & 0.020 \\
\hline Negative & Ref & & & Ref & & \\
\hline \multicolumn{7}{|l|}{ Number of people living with participant } \\
\hline 1 other person & 1.89 & $(1.00,3.59)$ & 0.05 & 1.56 & $(0.59,4.94)$ & 0.40 \\
\hline 2-3 other people & 5.23 & $(2.85,9.62)$ & $<.001$ & 6.04 & $(2.47,18.25)$ & $<.001$ \\
\hline $4-5$ other people & 9.8 & $(4.90,19.62)$ & $<.001$ & 10.28 & $(3.75,33.61)$ & $<.001$ \\
\hline
\end{tabular}


Table 3 (continued)

\begin{tabular}{|c|c|c|c|c|c|c|}
\hline & OR & $95 \% \mathrm{CI}$ & $p$ & $\mathrm{aOR}^{\mathrm{a}}$ & $95 \% \mathrm{CI}$ & $p$ \\
\hline $6+$ other people & 2.9 & $(0.97,8.67)$ & 0.06 & 2.47 & $(0.41,12.91)$ & 0.29 \\
\hline Lives alone & Ref & & & Ref & & \\
\hline
\end{tabular}

${ }^{\text {a }}$ Sample size for the adjusted model was 854 due to missing data

\section{Strengths and Limitations}

Our study has several strengths worth noting. This study is one of few to report unemployment and job loss for LGBTQ+ individuals instead of LGBTQ+ households, which do not fully represent the LGBTQ+ population (Lee et al., 2020). Additionally, this study draws on a large sample of LGBTQ+ individuals throughout the US and US territories. However, this study is not without limitations. First, a majority of our sample was white non-Hispanic and our recruitment method of internet-based groups may have resulted in sampling bias of participants, include those who could read and understand English and had the capability to use an internet-based survey. Second, because we did not collect job type or income for all participants, we cannot analyze differences in job loss by occupation type or income levels. Furthermore, unemployment has changed and will continue to change since the collection of data. However, we believe that recovery from job loss during the start of the pandemic will take time along with targeted interventions to individuals who are most vulnerable.

\section{Conclusions}

Our findings indicate that LGBTQ+ individuals experience a high rate of underemployment or unemployment due to COVID-19. This financial hardship exacerbates a public health crisis as it leads to further health and economic burdens, such as food insecurity (Mehta \& Chang, 2020), evictions (Riley et al., 2020), and loss of health insurance (Woolhandler \& Himmelstein, 2020). With about $31 \%$ of adults having a high likelihood of eviction or foreclosure (US Census Bureau, 2021a), LGBTQ+ individuals are especially vulnerable to eviction due to unemployment. US states that have lifted eviction moratoriums have seen an increase in COVID-19 cases and deaths compared to states that have not lifted the moratoriums (Leifheit et al., 2020). The LGBTQ+ population is not monolithic, and our analyses indicate greater economic vulnerabilities among certain subgroups suggesting that tailored approaches must be used to address the economic health in a population that is already economically underserved (Carpenter et al., 2020; Charlton et al., 2018; The Williams Institute, 2019). While our study provides critical knowledge, there is an ongoing need to advocate for the inclusion of SOGI demographic items in the US census and other large scale national data collection to accurately capture data with regard to the extent of the wellbeing of the population (Krause, 2021). Such data will also help provide support for the allocation of funding to support the health and wellbeing of LGBTQ+ individuals and populations (King, 2020; Sheckter et al., 2020). These structural changes are essential if we are to effectively understand the needs of LGBTQ+ populations which continue to experience marginalization and discrimination placing sexual and gender minority individuals at risk for underemployment and unemployment, and health inequity.

Author Contribution All authors have equally contributed to this article.

Availability of Data and Material Data are available upon request to the corresponding author.

Code Availability Code is available upon request to the corresponding author.

\section{Declarations}

All study activities were approved by the Institutional Review Board at Rutgers University. (\#Pro2020000920).

Conflict of Interest The authors declare no competing interests.

\section{References}

Abuelgasim, E., Saw, L. J., Shirke, M., Zeinah, M., \& Harky, A. (2020). COVID-19: Unique public health issues facing Black, Asian and minority ethnic communities. Current Problems in Cardiology, 45(8), 100621. https://doi.org/10.1016/j.cpcardiol.2020.100621

Ahmad, K., Erqou, S., Shah, N., Nazir, U., Morrison, A. R., Choudhary, G., \& Wu, W. C. (2020). Association of poor housing conditions with COVID-19 incidence and mortality across US counties. PLoS One, 15(11), e0241327. https://doi.org/10.1371/journal.pone.0241327

Badgett, M. V., Choi, S. K., \& Wilson, B. D. (2019). LGBT poverty in the United States. The Williams Institute. Retrieved Oct 23 from https://williamsinstitute.law.ucla.edu/publications/lgbtpoverty-us/

Cahill, S., Grasso, C., Keuroghlian, A., Sciortino, C., \& Mayer, K. (2020). Sexual and gender minority health in the COVID-19 pandemic: Why data collection and combatting discrimination matter now more than ever. American Journal of Public Health, 110(9), 1360-1361. https://doi.org/10.2105/AJPH.2020.305829

Carpenter, C. S., Eppink, S. T., \& Gonzales, G. (2020). Transgender status, gender identity, and socioeconomic outcomes in the United States. ILR Review, 73(3), 573-599. https://doi.org/10. 1177/0019793920902776 
Castellanos, H. D. (2016). The role of institutional placement, family conflict, and homosexuality in homelessness pathways among Latino LGBT youth in New York City. Journal of Homosexuality, 63(5), 601-632. https://doi.org/10.1080/00918369.2015. 1111108

CBS News. (2020). Patients getting slammed by surprise costs related to COVID-19. CBS News. Retrieved Dec 23 from https://www. cbsnews.com/news/patients-getting-slammed-by-surprise-costsrelated-to-covid-19/

Centers for Disease Control and Prevention. (2020a). COVID-19 case surveillance public use data. Centers for Disease Control and Prevention. Retrieved Jan 29 from https://data.cdc.gov/Case-Surveillance/ COVID-19-Case-Surveillance-Public-Use-Data/vbim-akqf

Centers for Disease Control and Prevention. (2020b). Loss of work due to illness. Centers for Disease Control and Prevention. Retrieved Jan 29 from https://www.cdc.gov/nchs/covid19/rands/work.htm

Charlton, B. M., Gordon, A. R., Reisner, S. L., Sarda, V., Samnaliev, M., \& Austin, S. B. (2018). Sexual orientation-related disparities in employment, health insurance, healthcare access and healthrelated quality of life: A cohort study of US male and female adolescents and young adults. BMJ Open, 8(6), e020418. https:// doi.org/10.1136/bmjopen-2017-020418

Chen, Y. H., Glymour, M., Riley, A., Balmes, J., Duchowny, K., Harrison, R., Matthay, E., \& Bibbins-Domingo, K. (2021). Excess mortality associated with the COVID-19 pandemic among Californians 18-65 years of age, by occupational sector and occupation: March through Oct 2020. medRxiv. https://doi.org/10.1101/2021.01.21.21250266

Clark, E., Fredricks, K., Woc-Colburn, L., Bottazzi, M. E., \& Weatherhead, J. (2020). Disproportionate impact of the COVID-19 pandemic on immigrant communities in the United States. PLoS Neglected Tropical Diseases, 14(7), e0008484. https://doi.org/10.1371/journal.pntd.0008484

Collins, S. R., Gunja, M. Z., \& Aboulafia, G. N. (2020). US health insurance coverage in 2020: A looming crisis in affordability. Retrieved Oct 23 from https://www.commonwealthfund.org/publications/ issue-briefs/2020/aug/looming-crisis-health-coverage-2020-biennial

Dickler, J. (2020). Nearly 14\% of Americans have wiped out their emergency savings during the pandemic: $C N B C+$ Acorns survey. CNBC. Retrieved Jan 29 from https://www.cnbc.com/2020/09/ 01/nearly-14percent-of-americans-have-wiped-out-emergencysavings-during-pandemic.html

Ecker, J., Aubry, T., \& Sylvestre, J. (2019). A review of the literature on LGBTQ adults who experience homelessness. Journal of Homosexuality, 66(3), 297-323. https://doi.org/10.1080/00918369.2017. 1413277

Fairlie, R. W., Couch, K., \& Xu, H. (2020). The impacts of COVID-19 on minority unemployment: First evidence from April 2020 CPS microdata (0898-2937).

Farmer, B. (2020). Hospital bills for uninsured COVID patients are covered, but no one tells them. Kaiser Health News. Retrieved Jan 29 from https://khn.org/news/hospital-bills-for-uninsured-covidpatients-are-covered-but-no-one-tells-them/

Florida, R. (2019). The real powerhouses that drive the world's economy. Bloomberg CityLab. Retrieved Oct 18 from https://www. bloomberg.com/news/articles/2019-02-28/mapping-the-megaregions-powering-the-world-s-economy

Foster, S. (2020). Survey: As coronavirus spreads, nearly 1 in 3 Americans admit to not seeking medical care due to cost. Bankrate. Retrieved Jan 29 from https://www.bankrate.com/surveys/ health-care-costs/

Ganson, K. T., Tsai, A. C., Weiser, S. D., Benabou, S. E., \& Nagata, J. M. (2021). Job insecurity and symptoms of anxiety and depression among U.S. young adults during COVID-19. Journal of Adolescent Health, 68(1), 53-56. https://doi.org/10.1016/j.jadohealth.2020.10.008

Garfield, R., Orgera, K., \& Damico, A. (2021). The coverage gap: Uninsured poor adults in states that do not expand Medicaid.
KFF Health System. Retrieved Oct 23 from https://www.kff.org/ medicaid/issue-brief/the-coverage-gap-uninsured-poor-adultsin-states-that-do-not-expand-medicaid/

Google. (2020). reCAPTCHA v3. Google. Retrieved Oct 18 from https://developers.google.com/recaptcha/docs/v3

Griffin-Tomas, M., Cahill, S., Kapadia, F., \& Halkitis, P. N. (2018). Access to health services among young adult gay men in New York City. American Journal of Men's Health, 13(1), 1557988318818683. https://doi.org/10.1177/1557988318818683

Griffin, M., Cahill, S., Kapadia, F., \& Halkitis, P. N. (2020a). Healthcare usage and satisfaction among young adult gay men in New York city. Journal of Gay \& Lesbian Social Services, 32(4), 531551. https://doi.org/10.1080/10538720.2020.1799474

Griffin, M., Jaiswal, J., Krytusa, D., Krause, K. D., Kapadia, F., \& Halkitis, P. N. (2020b). Healthcare experiences of urban young adult lesbians. Women's Health, 16, 1745506519899820. https:// doi.org/10.1177/1745506519899820

Griffin, M., Krause, K. D., Kapadia, F., \& Halkitis, P. N. (2018). A qualitative investigation of healthcare engagement among young adult gay men in New York City: A P18 Cohort Substudy. LGBT Health, 5(6), 368-374. https://doi.org/10.1089/lgbt.2017.0015

Griffin, M., Martino, R. J., LoSchiavo, C., Comer-Carruthers, C., Krause, K. D., Stults, C. B., \& Halkitis, P. N. (2021). Ensuring survey research data integrity in the era of internet bots. Quality \& Quantity. https://doi.org/10.1007/s11135-021-01252-1

Heck, J. E., Sell, R. L., \& Gorin, S. S. (2006). Health care access among individuals involved in same-sex relationships. American Journal of Public Health, 96(6), 1111-1118. https://doi.org/10. 2105/ajph.2005.062661

Hsu, H. E., Ashe, E. M., Silverstein, M., Hofman, M., Lange, S. J., Razzaghi, H., Mishuris, R. G., Davidoff, R., Parker, E. M., \& Penman-Aguilar, A. (2020). Race/ethnicity, underlying medical conditions, homelessness, and hospitalization status of adult patients with COVID-19 at an urban safety-net medical center-Boston, Massachusetts, 2020. Morbidity and Mortality Weekly Report, 69(27), 864-869.

Human Rights Campaign Foundation, \& PSB. (2020). The impact of COVID-19 on LGBTQ communities of color. Human Rights Campaign Foundation. Retrieved Jan 29 from https://assets2.hrc.org/files/assets/ resources/COVID_19_EconImpact-CommunitiesColor052020d.pdf

Jean, G. (1957). Megalopolis or the urbanization of the northeastern seaboard. Economic Geography, 33(3), 189-200. https://doi.org/ $10.2307 / 142307$

Jones, J. M. (2017). In U.S., $10.2 \%$ of LGBT adults now married to same-sex spouse. Retrieved Jan 29 from https://news.gallup.com/ poll/212702/lgbt-adults-married-sex-spouse.aspx

King, J. S. (2020). Covid-19 and the need for health care reform. New England Journal of Medicine, 382(26), e104. https://doi.org/10. 1056/NEJMp2000821

Kochhar, R., \& Barroso, A. (2020). Young workers likely to be hard hit as COVID-19 strikes a blow to restaurants and other service sector jobs. Pew Research Center. Retrieved Jan 29 from https:// www.pewresearch.org/fact-tank/2020/03/27/young-workerslikely-to-be-hard-hit-as-covid-19-strikes-a-blow-to-restaurantsand-other-service-sector-jobs/

Krause, K. D. (2021). Implications of the COVID-19 pandemic on LGBTQ communities. Journal of Public Health Management and Practice, 27. https://doi.org/10.1097/PHH.0000000000001273

Krause, K. D., Kapadia, F., Ompad, D. C., D’Avanzo, P. A., Duncan, D. T., \& Halkitis, P. N. (2016). Early life psychosocial stressors and housing instability among young sexual minority men: The P18 cohort study. Journal of Urban Health, 93(3), 511-525. https:// doi.org/10.1007/s11524-016-0049-6

Laurencin, C. T., \& McClinton, A. (2020). The COVID-19 pandemic: A call to action to identify and address racial and ethnic disparities. Journal of Racial Ethnic Health Disparities, 7(3), 398-402. https://doi.org/10.1007/s40615-020-00756-0 
Lee, J. G. L., Boynton, M. H., Shook-Sa, B. E., \& Wimark, T. (2020). Is where same-sex couples live a valid measure for where single lesbian, gay, and bisexual people live in population health research? Results from a National Probability Phone Survey, 2017, United States. Annals of LGBTQ Public and Population Health(2), 96-114. https://doi.org/10.1891/LGBTQ-2019-0009

Leifheit, K. M., Linton, S. L., Raifman, J., Schwartz, G., Benfer, E. A., Zimmerman, F. J., \& Pollack, C. (2020). Expiring eviction moratoriums and COVID-19 incidence and mortality. Available at SSRN 3739576.https://doi.org/10.2139/ssrn.3739576

Martino, R. J., Krause, K. D., Griffin, M., LoSchiavo, C., Comer-Carruthers, C., Karr, A. G., Bullock, A. F., \& Halkitis, P. N. (2021). A nationwide survey of COVID-19 testing in LGBTQ+ populations in the United States. Public Health Reports, 136(4), 493-507. https://doi.org/10.1177/00333549211018190

Mehta, J., \& Chang, A. (2020). For hungry Americans across the country, food insecurity crisis deepens. NPR. Retrieved Jan 29 from https://www.npr.org/sections/coronavirus-live-updates/ 2020/12/14/946420784/u-s-faces-food-insecurity-crisis-asseveral-federal-aid-programs-set-to-run-out-

Mirza, S. A., Zessoules, D., Hendricks, G., Madowitz, M., \& Durso, L. E. (2018). The state of the LGBTQ community in the labor market: Pre-June 2018 jobs day release. Retrieved Jan 29 from https://www.americanprogress.org/issues/economy/news/2018/ 07/05/453094/state-lgbtq-community-labor-market-pre-june2018-jobs-day-release/

Mojtabai, R. (2019). Insurance loss in the era of the affordable care act: Association with access to health services. Medical Care, 57(8), 567-573. https://doi.org/10.1097/mlr.0000000000001150

Mottola, G. R. (2014). The financial capability of young adults-A generational view. FINRA Foundation Financial Capability Insights.

Movement Advancement Project. (2020). The disproportionate impacts of COVID-19 on LGBTQ households in the U.S. Retrieved Jan 29 from https://www.lgbtmap.org/2020-covid-lgbtq-households

Nguyen, K. H., Trivedi, A. N., \& Shireman, T. I. (2018). Lesbian, gay, and bisexual adults report continued problems affording care despite coverage gains. Health Affairs, 37(8), 1306-1312. https:// doi.org/10.1377/hlthaff.2018.0281

Qualtrics. (2005). Qualtrics. In Provo, UT, USA (Version May-June 2020) https://www.qualtrics.com

Rader, B., Astley, C. M., Sy, K. T. L., Sewalk, K., Hswen, Y., Brownstein, J. S., \& Kraemer, M. U. G. (2020). Geographic access to United States SARS-CoV-2 testing sites highlights healthcare disparities and may bias transmission estimates. Journal of Travel Medicine, 27(7). https://doi.org/10.1093/jtm/taaa076

Riley, E. D., Hickey, M. D., Imbert, E., Clemenzi-Allen, A. A., \& Gandhi, M. (2020). COVID-19 and HIV spotlight the U.S. imperative for permanent affordable housing. Clinical Infectious Diseases. https:// doi.org/10.1093/cid/ciaa1327

Rodriguez-Diaz, C. E., Guilamo-Ramos, V., Mena, L., Hall, E., Honermann, B., Crowley, J. S., Baral, S., Prado, G. J., Marzan-Rodriguez, M., Beyrer, C., Sullivan, P. S., \& Millett, G. A. (2020). Risk for COVID19 infection and death among Latinos in the United States: examining heterogeneity in transmission dynamics. Annals of Epidemiology, 52(46-53), e42. https://doi.org/10.1016/j.annepidem.2020.07.007

Rodriguez, C. H. (2020). COVID tests are free, except when they're not. Kaiser Family Foundation. Retrieved Dec 23 from https://khn.org/news/ bill-of-the-month-covid19-tests-are-free-except-when-theyre-not/

Rossen, L. M., Branum, A. M., Ahmad, F. B., Sutton, P., \& Anderson, R. N. (2020). Excess deaths associated with COVID-19, by age and race and ethnicity-United States, 26 Jan-3 Oct 3, 2020. Morbidity and Mortality Weekly Report, 69(42), 1522.

Royal, J. (2020). Survey: Nearly 3 times as many Americans say they have less emergency savings versus more since pandemic. Bankrate.
Retrieved Jan 29 from https://www.bankrate.com/banking/savings/ emergency-savings-survey-2020/

Russell, S. T., \& Fish, J. N. (2016). Mental health in lesbian, gay, bisexual, and transgender (LGBT) youth. Annual Review of Clinical Psychology, 12(1), 465-487. https://doi.org/10.1146/annurevclinpsy-021815-093153

Sanchez, T. H., Zlotorzynska, M., Rai, M., \& Baral, S. D. (2020). Characterizing the impact of COVID-19 on men who have sex with men across the United States in April, 2020. AIDS and Behavior, 24(7), 2024-2032. https://doi.org/10.1007/s10461-020-02894-2

Santos, G. M., Ackerman, B., Rao, A., Wallach, S., Ayala, G., Lamontage, E., Garner, A., Holloway, I. W., Arreola, S., Silenzio, V., Strömdahl, S., Yu, L., Strong, C., Adamson, T., Yakusik, A., Doan, T. T., Huang, P., Cerasuolo, D., Bishop, A., Noori, T., Pharris, A., Aung, M., Dara, M., Chung, S. Y., Hanley, M., Baral, S., Beyrer, C., \& Howell, S. (2020). Economic, mental health, HIV prevention and HIV treatment impacts of COVID-19 and the COVID-19 response on a global sample of cisgender gay men and other men who have sex with men. AIDS and Behavior, 1-11. https://doi.org/10.1007/ s10461-020-02969-0

SAS Institute Inc. (2016). SAS 9.4 (Version TS1M5). In. Cary, NC.

Sheckter, C. C., Singh, P., Angelos, P., \& Offodile, A. C. (2020). Surprise billing in surgical care episodes - Overview, ethical concerns, and policy solutions in light of COVID-19. Annals of Surgery, 272(4). https://doi.org/10.1097/SLA.0000000000004152

Shiau, S., Krause, K. D., Valera, P., Swaminathan, S., \& Halkitis, P. N. (2020). The burden of COVID-19 in people living with HIV: A syndemic perspective. AIDS and Behavior, 24(8), 2244-2249. https://doi.org/10.1007/s10461-020-02871-9

Stettner, A., \& Pancotta, E. (2020). 12 million workers facing jobless benefit cliff on December 26. The Century Foundation. Retrieved Jan 29 from https://tcf.org/content/report/12-million-workers-facing-jobless-benefit-cliff-december-26/?agreed=1

Su, D., Irwin, J. A., Fisher, C., Ramos, A., Kelley, M., Mendoza, D. A. R., \& Coleman, J. D. (2016). Mental health disparities within the LGBT population: A comparison between transgender and nontransgender individuals. Transgender Health, 1(1), 12-20. https:// doi.org/10.1089/trgh.2015.0001

The Associated Press. (2020). Highlights of $\$ 900$ billion COVID-19 relief, wrapup bills. Associated Press. Retrieved Jan 29 from https://apnews.com/article/health-care-reform-health-legislationcoronavirus-pandemic-762f84e4da11d350d8b5be5680ab01c4

The White House. (2021). American rescue plan. Retrieved Mar 30 from https://www.whitehouse.gov/american-rescue-plan/

The Williams Institute. (2019). LGBT demographic data interactive. The Williams Institute, UCLA School of Law. Retrieved Jan 27 from https://williamsinstitute.law.ucla.edu/visualization/lgbtstats/?topic=LGBT\#about-the-data

Threet, D., Aurand, A., Pish, M., Allen, K., \& Carrol, S. (2020). Costs of COVID-19 evictions. National Low Income Housing Coalition. Retrieved Jan 29 from https://nlihc.org/sites/default/files/costs-ofcovid19-evictions.pdf

U.S. Census Bureau. (2021a). Week 26 household pulse survey: March 3 - November 15. U.S. Census Bureau. Retrieved Mar 30 from https://www.census.gov/data/tables/2021/demo/hhp/hhp26.html

U.S. Census Bureau. (2021b). Week 34 household pulse survey: July 21 - August 2 U.S. Census Bureau. Retrieved Oct 30 from https:// www.census.gov/data/tables/2021/demo/hhp/hhp34.html

U.S. Department of Health \& Human Services. (2020). CARES act provider relief fund: For patients. U.S. Department of Health \& Human Services. Retrieved Dec 23 from https://www.hhs.gov/ coronavirus/cares-act-provider-relief-fund/for-patients/index.html

U.S. Department of Labor. (2020a). The employment situation - May 2020. U.S. Department of Labor. Retrieved Jul 25 from https:// www.bls.gov/news.release/archives/empsit_06052020.pdf 
U.S. Department of Labor. (2020b). Unemployment insurance weekly claims. U.S. Department of Labor. Retrieved Jan 29 from https:// www.dol.gov/ui/data.pdf

U.S. Department of Treasury. (2020). The Treasury Department is delivering COVID-19 relief for all Americans. U.S. Department of Treasury. Retrieved Jan 29 from https://home.treasury.gov/ policy-issues/cares

U.S. Department of Treasury. (2021). FACT SHEET: The American rescue plan will deliver immediate economic relief to families. Retrieved Mar 30 from https://home.treasury.gov/ news/featured-stories/fact-sheet-the-american-rescue-planwill-deliver-immediate-economic-relief-to-families

United States Congess, 2019-2020 (2021). H.R.133 - Consolidated Appropriations Act, 2021. https://www.congress.gov/bill/116th-congress/ house-bill/133

Vahidy, F. S., Nicolas, J. C., Meeks, J. R., Khan, O., Pan, A., Jones, S. L., Masud, F., Sostman, H. D., Phillips, R., Andrieni, J. D., Kash, B. A., \& Nasir, K. (2020). Racial and ethnic disparities in
SARS-CoV-2 pandemic: analysis of a COVID-19 observational registry for a diverse US metropolitan population. BMJ Open, 10(8), e039849. https://doi.org/10.1136/bmjopen-2020-039849

Walters, M., Chen, J., \& Breiding, M. (2011). National intimate partner and sexual violence survey 2010: Findings on victimization by sexual orientation.

Whittington, C., Hadfield, K., \& Calderón, C. (2020). The lives \& livelihoods of many in the LGBTQ community are at risk amidst COVID-19 crisis. Human Rights Campaign Foundation. Retrieved Jan 29 from https://assets2.hrc.org/files/assets/resources/COVID19-IssueBrief032020-FINAL.pdf

Woolhandler, S., \& Himmelstein, D. U. (2020). Intersecting U.S. epidemics: COVID-19 and lack of health insurance. Annals of Internal Medicine, 173(1), 63-64. https://doi.org/10.7326/m20-1491

Publisher's Note Springer Nature remains neutral with regard to jurisdictional claims in published maps and institutional affiliations. 